\title{
A TRÍADE DO PROCESSO PER FORMULAS FORMULAE, PRAETORES, AEQUITAS
}

\author{
THE TRIAD OF PER FORMULAS PROCEDURE FORMULAE, PRAETORES, AEQUITAS
}

\author{
Austréia Magalhães Candido*
}

\begin{abstract}
Resumo:
O processo per formulas apresenta-se como a mais importante fase pela qual passou o sistema processual romano. Sua singularidade e seu brilho residem no fato de que é neste período que temos a mais intensa atividade dos iurisconsulti e, sobretudo, dos praetores, magistrados cuja atuação foi essencial para a transformação e perpetuação do Direito Romano até os nossos dias. Permeado pela noção de aequitas, o ius honorarium, por meio do Edito do Pretor, permitiu uma flexibilização do processo romano, suplantando pouco a pouco o rígido sistema anterior das legis actiones, fazendo com que o processo formular encarnasse a idéia do direito como a ars boni et aequi.
\end{abstract}

Palavras-Chave: Formula. Praetor. Aequitas. Litis Contestatio. Ações. Processo Civil Romano.

\begin{abstract}
:
The procedure per formulas appears as the most important phase undergone by the Roman court system. Its uniqueness and brilliance lies in the fact that this was the period in which the most intense activities of the iurisconsulti and, especially, of the praetor was performed. The Praetors were judges whose activities was essential for the transformation and perpetuation of Roman Law to the present day. Permeated by the notion of aequitas, the ius honorarium, by means of the Edict of the Praetor, allowed for a relaxation of the Roman procedures, gradually supplanting the previous rigid system of the legis actiones, thus causing the procedure per formulas to embody the idea of law as the ars boni et aequi.
\end{abstract}

Keywords: Formula. Praetor. Aequitas. Litis Contestatio. Actions. Roman Civil Procedure.

1. Introdução

O estudo do Direito Romano é, em geral, uma longa travessia rumo a um Direito cada vez mais flexível e, portanto, mais adaptável à vida moderna, cuja riqueza, proporcionada pelo desenvolvimento econômico-social, não permite uma tipificação absoluta, imutável, sob pena de levar à ruína o sistema jurídico vigente.

\footnotetext{
* Mestranda em Direito Romano pela Faculdade de Direito da Universidade de São Paulo. E-mail: austreia@ usp. br
} 
E é nesta consciência, nesta capacidade de adaptação que está a glória, o triunfo da iurisprudentia romana, capaz de criar um Direito sofisticado a tal ponto que profundas marcas e institutos originários desta época se fazem presentes em vários lugares do mundo em pleno século XXI.

Isso não se apresentou somente no que se refere ao campo do direito material, mas também no processual que, para os romanos, não se contrapunha ao direito material, pelo contrário, estava intrinsecamente ligado a ele, sem que pudéssemos falar na dualidade hoje existente entre direito e processo. ${ }^{1}$

Essa adaptabilidade fez, como se sabe, com que o processo civil romano passasse por três fases, ${ }^{2}$ a das legis actiones, a do processo per formulas e a da extraordinaria cognitio.

Neste trabalho, estudaremos o principal sistema processual da história romana, isto é, o processo per formulas, vigente durante todo o período clássico, profundamente influenciado pela noção de aequitas e que representa o auge da atuação de uma personagem fundamental ao progresso e à perpetuidade do Direito Romano, ou seja, a figura do pretor.

\section{Da origem do processo formular}

O procedimento formular inicia-se na segunda metade do século II a.C. vigendo até o século III d. C., isto é, do fim da República até Diocleciano. ${ }^{3}$

Sua origem se dá com a iurisdictio peregrina, ${ }^{4}$ já que com a expansão comercial de Roma, as relações com os estrangeiros acentuaram-se e um problema

\footnotetext{
O direito processual relacionava-se de maneira circular com o direito material, pois este, por vezes, estava na origem de uma ação, mas também uma ação poderia ser a origem de um direito, daí se afirmar que o Direito Romano era um sistema de ações, baseando-se, principalmente na célebre afirmação de Gaio que divide todo o Direito em pessoas, coisas e ações: Gai. 1,7-Omne autem ius, quo utimur, vel ad personas pertinet vel ad res vel ad actiones. (...). Todo Direito, porém, o qual é por nós utilizado, ou às pessoas, ou às coisas ou às ações pertence. (Tradução nossa). Cf. PUGLIESE, Giovanni. Diritto e Processo nell Esperienza Giuridica Romana. Diritto e Processo nella Esperienza Romana. Napoli: Jovene, 1994.

2 Lembrando que essas fases coexistiram e o advento de uma não significou, pois, o desaparecimento completo da anterior, sendo perceptível a convivência de dois sistemas em um mesmo período. Cf. CRUZ E TUCCI, José Rogério, AZEVEDO, Luiz Carlos de. Lições de História do Processo Civil Romano. São Paulo: Revsita dos Tribunais, 2001. p. 39-40.

3 Cf. ARANGIO-RUIZ, Vincenzo. Cours de Droit Romain (Les Actions). Napoli: Jovene, 1935. pp. 3. TALAMANCA, Mario. Processo Civile - Diritto Romano. Enciclopedia del Diritto. Milano: Giuffrè, 1987. v. XXXVI. p. 24.

4 É interessante observar que, como relembra TALAMANCA, Mario. op. cit., p. 26, o processo formular teve sua origem na iurisdictio peregrina, exercitada por um só pretor, ainda quando vigente o sistema das ações da lei, aplicável só aos cidadãos. Esse único pretor, quando confrontado com situações que envolviam estrangeiros, concedia, com base no seu imperium, a tutela pelo sistema formular. Com a intensificação das relações comerciais, esse único pretor não era mais suficiente para lidar com todos estes litígios envolvendo os não cidadãos, criando-se, pois, em 242 a.C. a figura do praetor peregrinus e é neste momento que esse pretor se contrapõe ao anterior, agora denominado de praetor urbanus. Logo, é na iurisdictio peregrina e
} 
começou a se esboçar, pois como tutelar as relações entre romanos e estrangeiros se as legis actiones, integrantes do ius civile, só eram aplicáveis aos cidadãos romanos?

É neste contexto, que o pretor, dotado do poder de imperium, ${ }^{5}$ cria um novo procedimento, o sistema formular, aplicável, primeiramente aos estrangeiros e depois, estendido aos cidadãos romanos, tornando-se o sistema oficial durante toda a época clássica.

Esse novo processo, proveniente do ius honorarium passa a vigorar nas relações entre os cives, segundo V. Arangio-Ruiz, ${ }^{6}$ por três motivos. Em primeiro lugar, no sistema das legis actiones havia a dificuldade de que se deveria pronunciar diante do magistrado sentenças solenes, as quais deveriam ser sabidas de cor, pois uma só palavra trocada impedia o prosseguimento da ação. ${ }^{7}$

Em segundo lugar, o sistema anterior dava preponderância ao pronunciamento das testemunhas na contestação da ação, o que importava em um grande exercício de memória e colocava a questão da boa-fé destes depoimentos, cuja veracidade era difícil de ser averiguada apesar das penas previstas para os testemunhos falsos. ${ }^{8}$

não com a criação do praetor peregrinus que se origina o procedimento per formulas. Cf. MARRONE, Matteo. Istituzioni di Diritto Romano. Firenze: Palumbo, 2006, p. 73.

5 TAlamAnCA, Mario. Lineamenti di Storia del Diritto Romano. Milano: Giuffrè, 1989. p. 138, lembra que o poder de imperium permitia, desde que fosse respeitada as garantias fundamentais dos cidadãos e a competência das demais magistraturas, que o pretor administrasse a cidade buscando livremente a forma mais adequada de exercer suas incumbências, incluindo a iurisdictio, sem estar vinculado aos preceitos do ius civile.

6 Cf. ARANGIO-RUIZ, Vincenzo. op. cit., p. 27-29.

7 As fontes relatam esse primeiro problema, como é possível averiguar na célebre descrição de Gai. 4, 11 - Actiones, quas in usu veteres habuerunt, legis actiones appellabantur, vel ideo, quod legibus proditae erant, quippe tunc edicta praetoris, quibus complures actiones introductae sunt, nondum in usu habebantur, vel ideo, quia ipsarum legum verbis accommodatae erant et ideo immutabiles proinde atque leges observabantur. Unde eum, qui de vitibus succisis ita egisset, ut in actione vites nominaret, responsum est rem perdidisse, cum [quia] debuisset arbores nominare eo, quod lex XII tavularum, ex qua de vitibus succisis actio competeret, generaliter de arboribus succisis loqueretur. As ações, as quais os antigos tinham em uso, chamadas de ações da lei, seja porque eram nascidas com as leis, pois naquele tempo os editos dos pretores, pelos quais várias ações foram introduzidas, ainda não eram tidos em uso, seja porque eram conformadas às palavras das próprias leis e por isso são consideradas imutáveis do mesmo modo que as leis. Daí aquele, o qual por causa das videiras cortadas agisse deste modo, que na ação denominasse videiras, foi respondido que perdesse o processo, pois deveria por ele ser denominada árvores, porque a Lei das XII Tábuas, a qual tratara da ação sobre videiras cortadas, de um modo geral sobre árvores cortadas falava. (Tradução nossa). E também em Gai. 4, 30 - Sed istae omnes legis actiones paulatim in odium venerunt: namque ex nimia subtilitate veterum, qui tunc iura condiderunt, eos res perducta est, ut vel qui minimum errasset litem perderet. Itaque per legem Aebutiam et duas Iulias sublatae sunt istae legis actiones, effectumque est, ut per concepta verba, is est per formulas, litigaremus. Mas todas estas ações da lei paulatinamente caíram em ódio: Com efeito, do extremo rigor dos antigos, os quais naquele tempo criaram o direito, chegou-se à situação (por eles ocasionada), de que quem o mínimo errasse perderia a demanda. E por isso, pela Lei Ebúcia e pelas duas Júlias foram suprimidas estas ações da lei, e foi estabelecido que por palavras redigidas, isto é, por fórmulas, litigaríamos. (Tradução nossa).

8 A Lei das XII Tábuas previa a pena para falso testemunho: T. 8, 23 - si nunc quoque-qui falsum testimonium dixisse convictus esset, e saxo Tarpeio deiceretur. Se também agora se estiver convencido que alguém tenha proferido um falso testemunho, da rocha Tarpéia seja [quem proferiu o falso testemunho] lançado. (Tradução nossa). 
E, por fim, a perda da importância das palavras solenes, ligadas, de início, aos rituais religiosos e à administração da justiça conferida aos pontífices, os quais perdem seu monopólio da justiça em favor de juristas laicos. ${ }^{9}$

Sendo assim, é com a Lex Aebutia, da segunda metade do século II a. C., que o processo per formulas adquire efeitos no campo do ius civile. Com esta lei, o processo formular torna-se facultativo em relação às legis actiones. ${ }^{10}$

Em 17 a.C., com a Lex Iulia iudiciorum privatorum, o procedimento per formulas torna-se o processo oficial e único com efeitos de ius civile no Direito Romano. ${ }^{11}$

\section{Características do Processo Per Formulas}

O processo formular caracteriza-se, tal como já ocorria com o sistema das legis actiones, ${ }^{12}$ por se desenvolver em duas fases, a saber, a fase in iure e a apud iudicem .

A primeira ocorria perante o pretor, o qual, com sua iurisdictio, fixava, juntamente com as partes, a fórmula. Pertencem a esta fase os seguintes atos: in ius vocatio, vadimonio, editio actiones, postulatio, confessio, infitiatio e litiscontestatio.

Pela in ius vocatio, chama-se o réu a participar da ação, funcionando como uma verdadeira citação. ${ }^{13}$ Este ato era de natureza privada, ${ }^{14}$ mas, ao contrário do que

9 Cf. CRUZ E TUCCI, José Rogério, AZEVEDO, Luiz Carlos de. op. cit., p.54. Cf. Pomp. l. s. enchir., D. $1,2,2,6$ e 7 .

10 Cf. TAlAMANCA, Mario. op. cit., p. 29-32. Essa é a opinião de M. Talamanca, no entanto, há autores, como MARRONE, Matteo. op. cit., p.73, que sustentam que a Lex Aebutia, na verdade, não tornou o processo formular facultativo, mas extinguiu as legis actiones per condicionem. Essa divergência, segundo BASTOS MEIRA, Silvio Augusto de. Processo Civil Romano. Belém: Falanzola, 1962. p. 50-51, deve-se ao fato de que no período entre a Lex Aebucia e a Lex Iulia iudiciorum privatorum, as legis actiones per manus injectionem e per pignoris capionem continuaram a ser utilizadas, no entanto, para o autor, que acompanha M. Talamanca, o processo formular era alternativo ao sistema das legis actiones até o advento da Lex Iulia iudiciorum privatorum.

11 Cf. TALAMANCA, Mario. op. cit., p. 32. O autor ressalta que, ainda nesta época, sobreviveram duas hipóteses para a aplicação das ações da lei, a saber, aquelas referentes ao iudicium centuvirale e a legis actio damni infecti. Tal evidencia-se em Gai. 4, 31 - Tantum ex duabus causis permissum est [id legis actionem facere] lege agere: damni infecti, et si centumvirale iudicium futurum est.(...). Somente em duas circunstâncias foi permitido [fazer isso por ação da lei] agir pela lei: na de dano infecto, e se for do tribunal dos centúnviros. (Tradução nossa).

12 Cf. TALAMANCA, Mario. op. cit., p. 22.

13 Cf. BASTOS MEIRA, Silvio Augusto de. op. cit., p. 52. Cf. também MARRONE, Matteo. op. cit., p. 75 e KASER, Max. Römisches Privatrecht. Tradução portuguesa de S. Rodrigues e F. Hämmerle. Lisboa: Calouste Gulbenkian, 1999. p. 439-440.

14 Cf. MARRONE, Matteo. op. cit., p. 74. Apesar de ser um ato, em si, privado, a in ius vocatio não poderia ser realizada sem a autorização do pretor, como afirma Gai. 4, 183 - In summa sciendum este eum, qui cum aliquo consistere velit, in ius vocatio oportere et eum, qui vocatus est, si non venerit, poenam ex edicto praetoris commitere. Quasdam tamen personas sine permissu praetoris in ius vocare non licet, veluti parentes patronos patronas, item liberos et parentes patroni patronaeve; et in eum, qui adversus ea egerit, poena constituitur. É necessário ainda saber isto, aquele que contra alguém queira apresentar-se, deve chamá-lo a juízo e aquele, o qual foi chamado, se não vier, incorre em pena oriunda do edito do pretor. Algumas pessoas, no entanto, sem a permissão do pretor não é permitido chamar a juízo, como os pais, os patronos, as patronas, do mesmo modo os livres e pais do patrono ou da patrona; e para aquele, que contra 
ocorria no período anterior, o autor da ação não era autorizado a fazer uso da força ${ }^{15}$ para trazer o réu a juízo. Com efeito, o réu ausente sofria uma penalidade imposta pelo pretor. ${ }^{16}$

Para evitar a exposição pública decorrente da in ius vocatio, poder-se-ia utilizar o vadimonium, uma promessa de que o réu, ou seu representante, compareceria em certo dia perante o juízo. Caso essa promessa não viesse acompanhada de caução e não fosse cumprida, teríamos o início de um procedimento de execução. ${ }^{17}$

A editio actionis era o conhecimento dado ao réu de qual fórmula havia sido escolhida contra ele. ${ }^{18}$

O início da ação dava-se com a postulatio, ou seja, a exposição oral da pretensão do autor perante o magistrado, apontando-se, em seguida, a fórmula desejada no álbum do pretor. ${ }^{19}$ Caso não houvesse fórmula que se enquadrasse na situação fática apresentada pelo autor, ou teríamos uma denegatio actionis, isto é, a rejeição do pedido, ou, caso o pretor achasse ser o caso digno de tutela, concederia uma actio in factum concepta. $^{20}$

isto agir, é estabelecida uma pena. (Tradução nossa).

15 T. 1, 2 - Ni it, antestamino. Igitur em capito. Não indo, tomem-se testemunhas. Então, apodere-se dele. (Tradução nossa). T. 1, 3 - Si calvitur pedemve struit, manum endo iacito. Se enganar ou fugir, lance a mão [sobre ele]. (Tradução nossa).

16 Pode-se ingressar com uma actio in factum como em Gai. 4,46 - (...) Ceterae quoque formulae, quae sub titulo de in ius vocando propositae sunt, in factum conceptae sunt, veluti adversus eum, qui in ius vocatus neque venerit neque vindicem dederit; item contra eum, qui vi exemerit eum qui in ius vocatur; et denique innumerabiles eius modi aliae formulae in albo proponuntur. Também outras fórmulas, as quais sob o título de chamamento a juízo são propostas, são in factum conceptae, como contra quem, que chamado a juízo nem viera nem dera fiador [vindex]; do mesmo modo contra aquele que retirou pela força alguém que foi chamado a juízo; e, em suma, inumeráveis outras fórmulas deste assunto são propostas no álbum. (Tradução nossa). Ou pode haver uma missio in possessionem, como em Ulp. 59 ad ed., D. 42, 4, 7, 18 - Idem Celsus existimat, si is, a quo hereditatem petere velim, latitat, commodissime fieri posse, ut in possessionem mittar rerum, quas pro herede vel pro possessore possidet: sed si dolo fecit, quo minus possideret, bona eius possidenda et vendenda sunt. O mesmo Celso estima, se aquele, a quem se queira pedir a herança, não comparece, comodamente se pode fazer com que se coloque em posse dos bens, os quais, seja a título de herdeiro ou de possuidor tenha a posse: mas se fez com dolo, de modo que não os possuísse, os bens dele serão possuídos e vendidos. (Tradução nossa).

17 Cf. ARANGIO-RUIZ, Vincenzo. op. cit., p. 61-62. A mesma função do vadimonium é apontada por MARRONE, Matteo. op. cit., pp.75, no entanto, KASER, Max. op. cit., p. 440 e BASTOS MEIRA, Silvio Augusto de. op. cit., p.52-53, esclarecem que não apenas em substituição à in ius vocatio era utilizado o vadimonium, mas também seu uso era constatado quando a fase in iure não podia ser concluída em um só dia, tendo-se de marcar uma nova data para o prosseguimento da causa. Neste caso, a promessa do pagamento de uma multa (garantida pelos fiadores, isto é, os vades) era feita a fim de garantir o novo comparecimento do réu. Para isso, cf. Gai. 4,184 e Gai. 4, 185.

18 Cf. BASTOS MEIRA, Silvio Augusto de. op. cit., p. 53. KASER, Max. op. cit., p. 440, aponta que o edere actionem deveria ocorrer antes da in ius vocatio, sendo ato obrigatório para o autor. Na verdade, ARANGIO-RUIZ, Vincenzo. op. cit., p. 62, nos dá notícia de que este ato era realizado duas vezes. A primeira é esta editio actionis apontada por M. Kaser, a segunda, que seria a definitiva, ocorreria quando a indicação da fórmula fosse feita já perante o magistrado, compondo a postulatio.

19 Cf. BASTOS MEIRA, Silvio Augusto de. op. cit., p. 53.

20 Cf. KASER, Max. op. cit., p. 440. 
O réu então poderia ou confessar - confessio - hipótese em que se procedia à execução sobre a pessoa do devedor ou à missio in possessionem. Ou poderia contestar - infitiatio - caso no qual a fórmula era concedida e o processo avançaria para a fase apud iudicem. ${ }^{21}$

Após todos estes atos, chega-se ao momento mais importante da fase in iure, a litis contestatio.

A litis contestatio é a fixação do litígio com a submissão das partes à sentença prolatada pelo iudex ou pelo tribunal. Trata-se de um decreto do pretor, pelo qual se concede juízo ao autor, sendo só neste momento que as partes vinculam-se ao juiz. ${ }^{22}$

Trata-se de um ato que exigia a colaboração ${ }^{23}$ de ambas as partes, já que o autor recitava a fórmula - iudicium dictare - o réu aceitava - iudicium accipere - cabendo ao pretor conceder o juízo - iudicium dare/dicere - ordenando a prolação de sentença com base na fórmula ao iudex ou ao tribunal. ${ }^{24}$

Os efeitos deste ato eram: vinculação das partes à sentença dada pelo juiz ou tribunal; preclusão impeditiva de proposição de nova demanda sobre o mesmo objeto; prolongamento da responsabilidade, pois ações não hereditárias passam a ser transmissíveis aos herdeiros e as com prazo definido tornam-se sem prazo. ${ }^{25}$

Passa-se, então, à segunda fase do procedimento formular, a fase apud iudicem, perante um tribunal ou um juiz singular, que contavam com a iudicatio, não concedida ao pretor.

21 Cf. BASTOS MEIRA, Silvio Augusto de. op. cit., p. 53. Além de confessar ou de contestar a ação, o réu também poderia realizar um juramento - iusiurandum - seja ele voluntário ou necessário. No necessário, caso o réu jure que nada deve, estará dispensado (esse juramento só poderia ser feito com a deferência do autor e autorização do pretor), podendo também devolver o juramento ao autor e, assim, o processo já se encaminharia a uma fase executória. Ademais, poderia nem contestar, nem confessar, mas apresentar uma exceptio, a ser incluída na fórmula e, a isso, o autor poderia requerer uma replicatio. Havia também a possibilidade do réu manter uma atitude passiva. Nesta hipótese, tratando-se de uma actio in rem, o réu perde a coisa, já que não pode ser forçado a defendê-la pelo fato da ação versar sobre direito real. No caso de uma actio in personam, o chamado indefensus pode ter de se submeter a um cárcere privado - ductio - concedido ao autor ou sofrer a execução forçada, isto é, a missio in bona. Cf. KASER, Max. op. cit., p. 441-443.

22 Cf. KASER, Max. op. cit., p. 444-446.

23 Discute-se uma eventual natureza contratual da litis contestatio, devido à essa necessidade de submissão voluntária à sentença dada na fase apud iudicem. BASTOS MEIRA, Silvio Augusto de. op. cit., p. 54, afirma claramente a natureza contratual da litis contestatio, no entanto, KASER, Max. op. cit., p. 445, sustenta que, apesar de alguns efeitos contratuais, não podemos visualizar a litis contestatio desta forma, pois as declarações de vontade das partes não seriam endereçadas a elas mesmas e sim ao pretor. A razão de ser deste ato é que, sendo os juízes pessoas privadas tal como as partes, só com a submissão voluntária destas últimas é que seria possível vinculá-las.

24 Cf. MARRONE, Matteo. op. cit., p. 77. KASER, Max. op. cit., p. 445-446, destaca que o termo iudicium pode significar, em processo romano, tanto o tribunal concedido às partes como a própria fórmula e seu conteúdo.

25 Cf. KASER, Max. op. cit., p. 444-447. 
Essa fase não apresentou grandes alterações em relação ao sistema das legis actiones, ${ }^{26}$ e é neste momento que se realizam as provas do processo. ${ }^{27}$

$\mathrm{O}$ juiz, ${ }^{28}$ analisando a fórmula enviada pelo pretor e, não podendo decidir fora dos parâmetros por ela determinados, condenará ou absolverá o réu ou ainda poderá declarar o célebre sibi non liquet, quando, apesar das provas, não tiver opinião a respeito da causa, caso em que se retorna à fase in iure para a indicação de novo juiz. ${ }^{29}$

\section{A Fórmula}

A fórmula, ${ }^{30}$ que dá nome a esse período do processo romano, consiste na fixação da questão controvertida, instruindo o iudex (e, pois, limitando o seu poder) na prolação da sentença.

Inicia-se pela nomeação do juiz - iudicis nominatio - seguindo basicamente este padrão: Lucius Ticius iudex esto. ${ }^{31}$

As Institutas de Gaio nos descrevem minuciosamente a composição das fórmulas, vejamos, pois, por meio deste iurisconsultus as partes integrantes de uma fórmula.

Gai. 4, 39 - Partes autem formularum hae sunt: demonstratio intentio adiudicatio condemnatio.

Estas são, pois, as partes das fórmulas: demonstratio, intentio, adiudicatio e condemnatio. ${ }^{32}$

26 Cf. ARANGIO-RUIZ, Vincenzo. op. cit., p. 68-69.

27 Os principais meios de provas eram: confissão, testemunhas, inspeção, documentos, sentenças anteriormente prolatadas, opinião pública, tortura e juramentos. Cf. BASTOS MEIRA, Silvio Augusto de. op. cit., p. 55 e CRUZ E TUCCI, José Rogério, AZEVEDO, Luiz Carlos de. op. cit., p. 125.

28 Existiam vários tipos de juízes, dentre os principais temos: o iudex unus/arbiter - particular a quem se confere a iudicatio, escolhido ou pelo pretor ou pelas partes, ou ainda por sorteio; os recuperatores colegiado de 3 a 11 juízes com competência para casos sobre a liberdade e alguns delitos; os centumviri - com competência para os processos sobre heranças e a querela inofficiosi testamenti, com 105 juízes, três para cada uma das 35 tribos, presidido pelo pretor urbano e os decemviri-com competência para processos sobre questões de liberdade, perdem a autonomia no processo formular e passam a presidir as comissões dos centumviri. Cf. KASER, Max. op. cit., p. 444.

29 Cf. ARANGIO-RUIZ, Vincenzo. op. cit., p. 68-69.

30 TALAMANCA, Mario. op. cit., p. 34, ressalta que dois termos são utilizados para designar a fórmula, a saber, formula e iudicium. A formula seria a fórmula abstrata prevista no Edito do pretor e o iudicium, a fórmula do caso concreto apresentada ao iudex.

31 Seja iudex Lúcio Tício (Tradução nossa). Cf. KASER, Max. op. cit., p. 448 e MARRONE, Matteo. op. cit., p. 80 .

32 Tradução nossa. 
Gai. 4, 40 - Demonstratio est ea pars formulae quae principio ideo inseritur, ut demonstretur res de qua agitur, veluti haec pars formulae: QUOD A. AGERIUS N. NEGIDIO HOMINEM VENDIDIT; item haec: QUOD A. AGERIUS APUD N. NEGIDIUM HOMINEM DEPOSUIT.

A demonstratio é aquela parte da fórmula a qual é inserida, por isso, no começo, para que seja indicada a questão da qual se trata, como esta parte da fórmula: PELO FATO DE A. AGÉRIO TER VENDIDO UM HOMEM; também esta: PELO FATO DE A. AGÉRIO JUNTO A N. NEGÍDIO ${ }^{33}$ TER DEPOSITADO UM HOMEM. ${ }^{34}$

Gai. 4, 41 - Intentio est ea pars formulae, qua actor desiderium suum concludit, veluti haec pars formulae: SI PARET N. NEGIDIUM A. AGERIO SESTERTIUM X MILIA DARE OPORTERE; item haec: QUIDQUID PARET N. NEGIDIUM A. AGERIO DARE FACERE OPORTERE; item haec: SI PARET HOMINEM EX IURE QUIRITIUM A. AGERII ESSE.

A intentio é aquela parte da fórmula, pela qual o autor encerra o seu desejo, como esta parte da fórmula: SE PARECER QUE N. NEGÍDIO À A. AGÉRIO 10 MIL SESTÉRCIOS DEVA DAR; também esta: TUDO O QUE PAREÇA QUE N. NEGÍDIO À A. AGÉRIO DEVA FAZER OU DAR; também esta: SE PARECER QUE O HOMEM PELO DIREITO QUIRITÁRIO É DE A. AGÉRIO. ${ }^{35}$

Gai. 4, 42 - Adiudicatio est ea pars formulae, qua permititur iudici rem alicui ex litigatoribus adiudicare: veluti si inter coheredes familiae erciscundae agatur, aut inter socios communi dividundo, aut inter vicinos finium regundorum. Nam illic ita est: QUANTUM ADIUDICARI OPORTET, IUDEX TITIO ADIUDICATO.

A adiudicatio é aquela parte da fórmula, pela qual é permitido ao juiz adjudicar o bem a um dos litigantes: como se entre co-herdeiros seja feita a ação de inventário e partilha, ou entre os sócios a de divisão do que é comum, ou entre vizinhos na demarcação dos limites. De fato, ela é assim: O QUANTO DEVA SER ADJUDICADO, JUIZ, ADJUDIQUE A TÍCIO. ${ }^{36}$

\footnotetext{
33 É interessante a observação de PUGLIESE, Giovanni. op. cit., p. 23-24, de que o nome Numerius Negidius dado ao réu possui o significado de aquele que se recusa, que nega o pagamento. Numerius é proveniente de numerare, isto é, pagar e Negidius é aquele que nega.

34 Tradução nossa.

35 Tradução nossa.

36 Tradução nossa.
} 
Gai. 4, 43 - Condemnatio est ea pars formulae, qua iudici condemnandi absolvendive potestas permittitur, veluti haec pars formulae: IUDEX N. NEGIDIUM A. AGERIO SESTERTIUM X MILIA CONDEMNA: SI NON PARET, ABSOLVE; item haec: IUDEX N. NEGIDIUM A. AGERIO DUMTAXAT X MILIA CONDEMNA: SI NON PARET, ABSOLVITO; item haec: IUDEX N. NEGIDIUM A. AGERIO CONDEMNATO et reliqua, ut non adiciatur DUMTAXAT X MILIA.

A condemnatio é aquela parte da fórmula, pela qual ao juiz é conferido o poder de condenar ou absolver, como esta parte da fórmula: JUIZ CONDENA N. NEGÍDIO [A DAR] 10 MIL SESTÉRCIOS À A. AGÉRIO: SE NÃO PARECER CONVENIENTE, ABSOLVA; também esta: JUIZ, CONDENA N. NEGÍDIO EM RELAÇÃO À A. AGÉRIO A SOMENTE 10 MIL SESTÉRCIOS: SE NÃO PARECER CONVENIENTE, ABSOLVA; também esta: JUIZ, CONDENA N. NEGÍDIO EM RELAÇÃO À A. AGÉRIO e o restante, de modo que não seja acrescentado SOMENTE 10 MIL [SESTÉRCIOS]. ${ }^{37}$

É preciso observar que nem todas essas partes precisam estar presentes na fórmula, sendo possível, por exemplo, fórmulas sem a adiudicatio. ${ }^{38}$

Gaio também menciona as chamadas partes acidentais das fórmulas, a saber, as praescriptiones pro actore et pro reo e as exceptiones.

As praescriptiones limitam os efeitos da litis contestatio à res in iudicium deducta, ou seja, trata-se de uma cláusula colocada no início da fórmula, quando pro reo, com a finalidade de inserir um fato, não abarcado pela fórmula, e que impede a condenação do réu. Já quando pro actore, tem por função limitar o efeito preclusivo da litis contestatio somente ao fato questionado pelo autor. ${ }^{39}$

Eis o que nos explicam as fontes:

Gai. 4,131 - Saepe enim ex una eademque obligatione aliquid iam praestari oportet, aliquid in futura praestatione est: veluti cum in singulos annos vel menses certam pecuniam stipulati fuerimus; nam finitis quibusdam annis aut mensibus huius quidem temporis pecuniam praestari oportet, futurorum autem annorum sane quidem obligatio contracta intellegitur, praestatio vero adhuc nulla est. Si ergo velimus id quidem, quod praestari oportet, petere et in iudicium deducere, futuram vero obligationes praestationem in integro relinquere, necesse est ut cum hac praescriptione agamus: EA RES AGATUR, CUIUS

\footnotetext{
37 Tradução nossa.

38 E também é possível encontrar fórmulas sem a intentio, como na actio iniuriarum. Cf. KASER, Max. op. cit., p. 449.

39 Cf. TALAMANCA, Mario. op. cit., p. 38-39.
} 
REI DIES fuit; aliquodam si sine hac praescriptione egerimus, ea scilicet formula qua incertum petimus, cuius intentio his verbis concepta est: QUIDQUID PARET N. NEGIDIUM A. AGERIO DARE FACERE OPORTERE, totam obligationem, id est etiam futuram, in hoc iudicium deducimus, et quae ante tempus obligationis finitum in iudicium deducitur, ex ea condemnatio fieri non potest, neque iterum de ea agi potest.

De fato, frequentemente, de uma mesma obrigação uma parte imediatamente deve ser cumprida, [e] uma parte numa futura prestação está: como quando a cada ano ou meses certa pecúnia tenhamos estipulado; com efeito, tendo terminado os anos ou meses, deste prazo, certamente, deve ser paga a pecúnia, nos anos futuros, porém, sem dúvida, entende-se, pois, [haver] obrigação contraída, a prestação, no entanto, ainda é inexistente (inexigível). Se, portanto, quisermos, de fato, isto (as prestações hoje exigíveis), porque devem ser cumpridas, pedir e em juízo deduzir, deixando, porém, íntegras as futuras prestações, é necessário que ajamos com esta praescriptione: ESTA AÇÃO É FEITA EM RELAÇÃO À PRESTAÇÃO DE CUJOS DIAS [JÁ] FORAM, de outra forma se sem esta praescriptione agimos, esta fórmula, certamente, na qual pedimos [coisa] incerta, cuja intentio é concebida com estas palavras: TUDO O QUE PARECER QUE N. NEGÍDIO DEVA DAR OU FAZER À A. AGÉRIO, toda a obrigação, isto é, também a futura, deduzimos neste juízo, e quanto aquelas [prestações] que são deduzidas em juízo antes de terminado o prazo da obrigação, não se pode obter a condenação, nem, por uma segunda vez, a respeito delas se pode agir. ${ }^{40}$

Gai. 4, 133-Sed his quidem temporibus, sicut supraquoque notavimus, omnes praescriptiones ab actore proficiscuntur. Olim autem quaedam et pro reo opponebantur, qualis illa erat praescriptio: EA RES AGATUR, SI in ea re PRAEIUDICIUM HEREDITATI NON FIAT, quae nunc in speciem exceptionis deducta est et locum habet, cum petititor hereditatis alio genere iudicii praeiudicium hereditati faciat, veluti cum singulas res petat; est enim iniquum per unius rei petitionem universae hereditati praeiudicium fieri.

Mas, nestes tempos, de fato, como, porém, notamos acima, todas as praescriptiones são provenientes do autor. Outrora, no entanto, algumas também eram opostas pelo réu: QUE ESTA AÇÃO SEJA FEITA, SE NESTA AÇÃO NÃO FOR FEITO PREJUÍZO (PREJULGAR) À HERANÇA, a qual é agora deduzida em forma de exceção e tem lugar quando quem pede a herança prejulga-a em outro juízo, como quando peça bens singulares; é, de fato, iníquo, que pelo pedido de uma coisa, se prejulgue a universalidade da herança. ${ }^{41}$

\footnotetext{
40 Tradução nossa.
}

41 Tradução nossa. 
Já as exceptiones possuem a mesma função que as praescriptiones pro reo no que se refere ao acréscimo de fatos não previstos na fórmula. No entanto, ao contrário das praescriptiones, não objetivam uma limitação dos efeitos da litis contestatio, mas apenas a apresentação de um fato impeditivo da condenação. ${ }^{42}$

Gai. 4, 116 - Comparatae sunt autem exceptiones defendorum eorum gratia, cum quibus agitur. Saepe enim accidit, ut quis iure civili teneantur, sed iniquum sit eum iudicio condemnari. Veluti si stipulatus sim a te pecuniam tamquam credendi causa numeratus, nec numeravim; nam eam pecuniam a te peti posse certum est, dare enim te oportet, cum ex stipulatu teneris; sed quia iniquum est te eo nomine condemnari, placet per exceptionem doli mali te defendi debere.

Foram, porém, estabelecidas as exceptiones ${ }^{43}$ em favor da defesa deles (dos réus), com as quais se age. De fato, muitas vezes acontece de alguém pelo direito civil ser submetido (ser acionado), mas seja iníquo condená-lo em juízo. Como se eu estipulasse (prometesse) a ti uma quantia contada a título de empréstimo, e não emprestasse; de fato, esta quantia a ti é certo que posso pedir, pois tu deves dar, já que tens uma estipulação; mas porque é iníquo condenar-te a este título, é aceitável que devas ser defendido pela exceção de dolo mau. ${ }^{44}$

Outro detalhe a ser observado é que existem vários tipos de fórmulas. As principais são: in factum concepta, in ius concepta, arbitraria, ficticia, com transposição de sujeitos e praeiudiciales.

As fórmulas in factum conceptae são aquelas nas quais não se discute a existência de um direito ou obrigação, mas o reconhecimento de um fato, descrito na intentio. ${ }^{45}$ Muitas destas fórmulas serviram para tutelar situações não protegidas seja pelo ius civile seja pelo ius gentium. ${ }^{46}$

Por outro lado, quando a questão é a existência de um direito ou obrigação, temos as fórmulas in ius conceptae. São fórmulas típicas do ius civile, ao contrário das anteriores, provenientes do ius honorarium. ${ }^{47}$

42 Cf. TALAMANCA, Mario. op. cit., p. 41.

43 MEIRA, Silvio Augusto de Bastos. op. cit., p. 71, elenca as possíveis exceptiones: exceptio quod metus causa, exceptio doli mali, exceptio de violação de lei ou senatusconsulto, exceptio pactum conventum, exceptio res iudicata, exceptio res in iudidium deducta, exceptio litis dividuae, exceptio litis residuae e exceptio cognitoriae.

44 Tradução nossa.

45 Cf. TALAMANCA, Mario. op. cit., p. 54.

46 Cf. ARANGIO-RUIZ, Vincenzo. op. cit., p. 55.

47 Cf. TALAMANCA, Mario. op. cit., p. 54. Gaio faz a diferenciação entre esses dois tipos de fórmula: Gai. 4,45 - Sed eas quidem formulas, in quibus de iure quaeritur, in ius conceptas vocamus, quales sunt, quibus intendimus nostrum esse aliquid ex iure Quiritium aut nobis dari oportere aut pro fure damnum decidi oportere; sunt et aliae, in quibus iuris civilis intentio est. Mas, de fato, estas fórmulas, nas quais questiona- 
Já as formulae arbitrariae tem lugar quando, na realidade, se deseja a restituição de um bem ou qualquer outra prestação, sendo assim, a condenação pecuniária (a única, a princípio, possível no processo formular) só ocorre se não for cumprido o iussum de restituendo, isto é, se não for feita a devolução do bem ou satisfeito o interesse do credor. $^{48}$

Falamos em formulae ficticiae quando temos presente na redação da fórmula uma ficção jurídica, como a de que o prazo de usucapião já ocorrera, entre outras. ${ }^{49}$

A transposição de sujeitos se dá, por sua vez, quando as pessoas integrantes da intentio ou da demonstratio são diversas das indicadas na condemnatio. É o caso típico das ações noxais, ${ }^{50}$ como nas hipóteses nas quais a condenação recai sobre o paterfamilias ou o dominus por atos dos filii ou dos servi. ${ }^{51}$

Por fim, temos as fórmulas praeiudiciales. São fórmulas que possuem somente a intentio, na qual se quer determinar uma situação de fato ou de direito. Versam,

se sobre o direito, in ius conceptae chamamos, como são aquelas, nas quais pretendemos que algo seja nosso pelo direito dos Quirites ou deva nos dar [algo] ou que deva ser decidido o dano por causa de furto; existem também outras, nas quais está na intentio [alguma coisa] de direito civil. (Tradução nossa). Gai. 4,46 - Ceteras vero in factum conceptas vocamus, id est in quibus nulla talis intentio concepta est, sed initio formulae nominatio eo, quod factum est, adiciuntur ea verba, qua utitur patronus contra libertum, qui eum contra edictum praetoris in ius vocavit; nam in ea ita est: RECUPERATORES SUNTO. SI PARET ILLUM PATRONUM AB ILLO LIBERTO CONTRA EDICTUM ILLIUS PRAETORIS IUS VOCATUM ESSE, RECUPERATORES ILLUM LIBERTUM ILLI PATRONO SESTERTIUM X MILIA CONDEMNATE: SI NON PARET, ABSOLVITE. (...). Outras, de fato, chamamos de in factum conceptae, isto é, aquelas nas quais não é concebida uma intentio deste tipo, mas no início da fórmula é designado aquilo que é fato, acrescentando-se estas palavras, as quais são utilizadas pelo dono contra o escravo que o chamou em juízo, contra o edito do pretor; pois, ela é assim: SÊDES RECUPERATORES. SE PARECER QUE AQUELE PATRONO POR AQUELE ESCRAVO CONTRA O EDITO DAQUELE PRETOR FOI CHAMADO A JUÍZO, RECUPERATORES AQUELE LIBERTO CONDENAI (A PAGAR) 10 MIL SESTÉRCIOS A AQUELE PATRONO: SE NÃO PARECER, ABSOLVEI. (Tradução nossa).

48 Cf. TALAMANCA, Mario. op. cit., p.65-66.

49 Id. Ibid., p. 56.

50 A origem das ações noxais, tal como ocorria com os escravos, estava no fato de que o filius, como não possuía patrimônio próprio, não era capaz de pagar a pena oriunda do delito cometido, não podendo, pois, ser sujeito passivo de um oportere, derivado da fórmula das ações noxais. Sendo assim, no período clássico, não era possível punir diretamente um filius sem a autorização do pater, titular do poder sobre o culpado pelo delito, logo, a entrega representava a cessação deste impedimento de punição direta. Tal direito é relatado por Gaio, em Gai. 4,75. Ex maleficio filiorum familias servorumque, veluti si furtum fecerint aut iniuriam commiserint, noxales actiones proditae sunt, uti liceret patri dominove aut litis aestimationem sufferre aut noxae dedere. Erat enim iniquum nequitiam eorum ultra ipsorum corpora parentibus dominisve damnosam esse. Por causa do prejuízo dos filifamilias ou dos escravos, como quando realizassem um furto ou cometessem injúria, foram apresentadas as ações noxais, de modo que se permite ao pai ou ao dono ou suportar a avaliação da lide ou entregar em noxa. De fato, era iníquo que o desregramento deles, além dos próprios corpos, aos pais ou aos donos fosse danoso. (Tradução nossa). Cf. BIONDI, Biondo. Noxa. Novissimo Digesto Italiano. Torino: UTET, 1957. v. XI. p. 449 e PUGLIESE, Giovanni. Obbligazione del Capo Famiglia e Responsabilità Diretta del Colpevole nel Regime della Nossalità. Studi in Memoria di Emilio Albertario. Milano: Giuffrè, 1953. v. 1. p. 267-268.

51 Id. Ibid., p. 59-60. 
principalmente, sobre ações que objetivam verificar o status de uma pessoa, ou para determinar o valor de um bem, sendo prévias a um processo de execução. ${ }^{52}$

\section{Ações}

Já mencionamos os diversos tipos de fórmulas existentes neste período, agora, vamos discorrer sobre três tipos de ações, ${ }^{53}$ as edictales, as decretales e as utiles, sobretudo, pelo papel central do pretor, na sua construção. ${ }^{54}$

As ações editais nada mais são, como o próprio nome sugere, do que aquelas cujas fórmulas estão contidas no Edito do Pretor. ${ }^{55}$ Podem ser oriundas tanto do ius civile como do ius honorarium. ${ }^{56}$

Por sua vez, as decretais, também chamadas de actiones in factum, são as ações não previstas no Edito, concedidas, pois, com base no caso concreto apresentado ao pretor. Por esse motivo, obviamente, nunca terão por base questões do ius civile. ${ }^{57}$

Enfim, temos as actiones utiles, que são ações provenientes de uma extensão, por analogia, de uma ação edital, seja do ius civile seja do ius honorarium, a casos não previstos e, por esse motivo, são sempre ações pretorianas. ${ }^{58}$ As fórmulas fictícias e com transposição de sujeitos seriam exemplos de ações úteis. ${ }^{59}$

52 Id. Ibid., p. 68-69. As fontes apresentam a descrição deste tipo de fórmula: Gai. 4, 44 - Non tamen istae omnes partes simul inveniuntur, sed quaedam inveniuntur, quedam non inveniuntur. Certe intentio aliquando sola inveniuntur, sicut in praeiudicialibus formulis, qualis est qua quaeritur, aliquis libertus sit, vel quanta dos sit, et aliae complures. (...). Não, porém, todas estas partes simultaneamente são encontradas. Certamente a intentio algumas vezes sozinha é encontrada, como nas fórmulas praeiudiciales, onde, de tal forma seja questionado, se alguém é liberto, ou de quanto é o dote, e outras tantas. (...). (Tradução nossa).

53 Eis a definição do termo ação: Cels. 3 dig., D. 44, 7, 51 - Nihil aliud est actio quam ius quod sibi debeatur iudicio persequendi. Uma ação nada é senão o direito de aquilo que a alguém é devido, perseguir em juízo. (Tradução nossa).

54 Outras classificações existem, além das três mencionadas, a saber, actiones in rem e in personam, que correspondem, respectivamente às vindicationes e condictiones do sistema processual anterior, actiones civiles e actiones honorariae, ações penais cujo objetivo é a aplicação de uma pena, as ações reipersecutórias, nas quais se visa à recuperação de um bem ou de seu valor, e ações mistas em que se deseja tanto uma pena como um bem ou seu valor, cujo exemplo mais célebre é a actio ex lege Aquilia. Cf. GIFFARD, André. Études de Droit Romain. Paris: Cujas, 1972. p. 63-65.ARANGIO-RUIZ, Vincenzo. op. cit., p. 88-90, ainda acrescenta a categoria de ações de direito estrito e ações de boa-fé.

55 É interessante observar o que continha o Edito do Pretor, como nos mostra BASTOS MEIRA, Silvio Augusto de. História e Fontes do Direito Romano. São Paulo: Saraiva, 1966. p. 135: esses editos continham, em primeiro lugar, as fórmulas, em segundo, a promessa do pretor de conceder certas exceptiones, em terceiro, a promessa de corrigir, suprir e flexibilizar o ius civile e, por fim, a promessa de conceder stipulationes praetoriae, interdictae, missiones in possessionem, restitutiones in integrum.

56 Cf. TALAMANCA, Mario. op. cit., p. 52-53.

57 Id. Ibid., p.53. Com base nesta diferenciação, temos três tipos de Editos, a saber, o edictum repentinum, usado em casos não previstos no segundo tipo, isto é, no edictum perpetuum, o qual era adotado por um ano (não confundir com o Edictum Perpetuum de Sálvio Juliano), prazo do cargo do magistrado que o elaborou. No entanto, quando o pretor seguinte aproveitava o Edito do ano anterior, tínhamos o edictum tralaticium. Cf. BASTOS MEIRA, Silvio Augusto de. op. cit., p. 134.

58 Cf. TALAMANCA, Mario. op. cit., p. 62-63.

59 Cf. SURGIK, Aloísio. Lineamentos do Processo Civil Romano. Curitiba: Livro é Cultura, 1990. p. 83. 
A principal personagem do sistema formular é, sem dúvida, o praetor, ${ }^{60}$ sendo interessante, pois, nos determos um instante no desenvolvimento de suas funções.

Inicialmente, o rei era o único a possuir o poder de imperium, composto de três partes, a saber, a sacral (sacra), a militar (militia) e a judiciária, isto é, o ius reddere. No entanto, com o fim da monarquia, foram criados três magistrados, todos eles com o poder de imperium completo. ${ }^{61}$

Mas, o exercício de administração da justiça tornava necessária a presença permanente de um dos magistrados em Roma, o que não seria possível, caso os três magistrados exercessem funções militares em um tempo pleno de guerras. ${ }^{62}$

Sendo assim, destaca-se dos demais o ius reddere. E é neste momento, que temos a criação do praetor urbanus, ${ }^{63}$ o qual passa a ser considerado conlega minor dos outros dois magistrados, ou seja, dos cônsules. ${ }^{64}$

Como toda magistratura, a pretura era reservada aos patrícios até que em 367 a.C., com a Lex Licinia Sextia de consule plebeio, autoriza-se a eleição de plebeus para o cargo. Em 337 a.C., elege-se Quintus Publilius Philo, o primeiro pretor plebeu. ${ }^{65}$

Além do poder de imperium, o pretor possuía a potestas, na qual se incluía o chamado ius edicendi, ${ }^{66}$ de caráter mais legislativo, restrito ao direito privado. ${ }^{67}$

60 Derivado do verbo eo,is, ii, ire, isto é, do verbo ir, praetor é aquele que vai à frente do exército. Cf. FARIA, Ernesto. Vocabulário Latino-Português. Rio de Janeiro: Briguiet, 1943. p. 90-91. Há uma discussão sobre a origem deste termo, que nos é apresentada por SCARLATA FAZIO, Mariano. Praetor. Novissimo Digesto Italiano. Torino: UTET, 1965. v. XIII. p. 549, pois haveria a tese de que o termo não derivaria do verbo ire/ praeire, mas de dois termos gregos, os quais significariam ou juiz ou senhor, ou igualando praetor à is, qui verbis praeit. No entanto, as duas últimas acepções, para o autor, referem-se a questões sagradas, não se relacionando com o pretor tal como o conhecemos e a primeira acepção só seria encontrada em Sófocles, sendo improvável, portanto, que o termo derive de qualquer outra acepção a não ser a do verbo ire.

61 Cf. SCARLATA FAZIO, Mariano. op. cit., p. 550.

62 Id. Ibid., p. 550.

63 É interessante observar que alguns autores, como ARANGIO-RUIZ, Vincenzo. Pretore. Enciclopedia Italiana di Scienze, Lettere ed Arti. Roma: Treccani, 1935. p. 221, atribuem a criação do pretor com função unicamente jurisdicional, somente em 367 a.C., com a Lex Licinia Sextia de consule plebeio. O mesmo aparece no verbete Praetor. Nuovo Digesto Italiano. Torino: UTET, 1939, p. 117 (sem indicação de autor). No entanto, SCARLATA FAZIO, Mariano. op. cit., p. 550, afirma ser estranho que a necessidade de um magistrado fixo na cidade de Roma só aparecesse nesta época, pois as guerras envolvendo Roma já aconteciam há muito tempo, levando esses magistrados a se ausentarem da cidade.

64 Cf. SCARLATA FAZIO, Mariano. op. cit., p. 550.

65 Cf. TALAMANCA, Mario. op. cit., p. 131.

66 Também possuíam o ius edicendi os cônsules, os censores, o edis curules, os governadores de província e, posteriormente, os imperadores. Cf. MEIRA, Silvio Augusto de Bastos. op. cit., p. 134.

${ }^{67}$ Praetor. op. cit., p. 117. 
É importante observar que, apesar de em 242 a.C. criar-se o praetor peregrinus ${ }^{68}$ a pretura tem como característica o fato de não consistir em uma colegialidade, ${ }^{69}$ sendo a única magistratura ordinária deste tipo. ${ }^{70}$

Com o passar do tempo, o número de pretores foi aumentando, principalmente, quando da conquista das províncias da Sicília, da Sardenha, da Espanha e de Narbona, ${ }^{71}$ atingindo-se um total de 17 pretores $^{72}$ na época de Tito. ${ }^{73}$

O direito pretoriano, que não se confunde com o ius honorarium, ${ }^{74}$ passa a exercer papel fundamental no desenvolvimento do processo per formulas, com a produção dos célebres Editos do Pretor.

O Edito do Pretor era uma publicação anual deste magistrado, no qual havia as indicações de como se daria o exercício de sua função para o ano ${ }^{75}$ em que havia sido eleito.

68 Cf. Pomp., l. s. enchir., D. 1,2,2,27 e 28.

69 Cf. ARANGIO-RUIZ, Vincenzo, op. cit., p. 221, afirma que também a pretura transforma-se em uma magistratura colegial, principalmente quando da criação do pretor peregrino.

70 Cf. SCARLATA FAZIO, Mariano. op. cit., p. 550 e TALAMANCA, Mario. op. cit., p. 131-132.

71 Cf. SCARLATA FAZIO, Mariano. op. cit., p. 552.

72 Tanto ARANGIO-RUIZ, Vincenzo, op. cit., p. 221 como TALAMANCA, Mario. op. cit., p. 132, afirmam que o número total de pretores era de 8 (apesar de V. Arangio-Ruiz admitir o aumento do número de pretores para 16, quando passam a cuidar de matéria penal). Provavelmente, esses autores constatam o problema verificado por Cf. SCARLATA FAZIO, Mariano. op. cit., p. 552, de que houve um afastamento, a partir de Júlio César, entre o pretor e a função de iurisdictio, pois dentre esses 18 pretores, tínhamos praetoris aerarii, praetores fideicommissarii e um praetor tutelaris. O autor aponta, então, uma perda paulatina das características típicas do pretor, tal como das demais magistraturas.

73 Pomp., l. s. enchir., D. 1,2,2,32 - Capta deinde Sardinia mox Sicilia, item Hispania, deinde Narbonensi provincia totidem praetores, quot provinciae in dicionem venerant, creati sunt, partim qui urbanis rebus, partim qui provincialibus praeessent. Deinde Cornelius Sulla quaestiones publicas constituit, veluti de falso, de parricidio, de sicariis, et praetores quattuor adiecit. Deinde Gaius Iulius Caesar duos praetores et duos aediles qui frumento praeessent et a Cerere cereales constituit. Ita duodecim praetores, sex aediles sunt creati. Divus deinde Augustus sedecim praetores constituit. Post deinde divus Claudius duos praetores adiecit qui de fideicommisso ius dicerent, ex quibus unum divus Titus detraxit: et adiecit divus Nerva qui inter fiscum et privatos ius diceret. Ita decem et octo praetores in civitate ius dicunt. Conquistadas, em seguida, a Sardegna, logo depois a Sicília, também a Espanha, em seguida a província de Narbona precisamente tantos pretores, quantas províncias em domínio vieram, foram criados, uns que seriam encarregados dos assuntos da cidade e outros dos das províncias. Logo depois, Cornelius Sulla constituiu as questões públicas, como a de falsidade, a de parricídio, a de assassinos, e quatro pretores acrescentou. Posteriormente, Gaius Iulius Caesar, dois pretores e dois edis, os quais estariam encarregados dos grãos e [do que por causa de] Cerere [são] cereais, constituiu. Assim, doze pretores, seis edis foram criados. Depois, o Divino Augustus instituiu dezesseis pretores. Em seguida, o divino Claudius dois pretores acrescentou, os quais sobre fideicomisso diziam o direito, dentre os quais um o divino Titus subtraiu: e acrescentou um o divino Nerva que entre o fisco e os privados dizia o direito. Assim, dezoito pretores na cidade diziam o direito. (Tradução nossa).

74 O ius honorarium é o direito proveniente dos editos de todos os magistrados e não só o do pretor. Já o ius praetorium restringe-se ao Edito do Pretor. Cf. MEIRA, Silvio Augusto de Bastos. op. cit., p. 134-135 e Pap. 2 definit., D. 1,1,7,1 - Ius praetorium est, quod praetores introduxerunt adiuvandi vel supplendi vel corrigendi iuris civilis gratia propter utilitatem publicam. Quod et honorarium dicitur ad honorem praetorum sic nominatum. O direito pretoriano é aquele que os pretores introduziram auxiliando ou suprindo ou corrigindo o ius civile em razão da utilidade pública. O qual é chamado também de honorário, devido ao honor da pretura é assim denominado. (Tradução nossa).

75 Os pretores iniciavam seu mandato nas Calendas de janeiro, isto é, dia $1^{\circ}$ de janeiro. Cf. MELILLO, 
Proveniente do ius edicendi, inicialmente a comunicação do pretor era oral, em um segundo momento, passa a ser escrita no album, ${ }^{76}$ para que qualquer pessoa o pudesse ler. ${ }^{77}$

Os editos surgiram provavelmente entre o III e II séculos a.C., existindo tanto o edito do pretor urbano quanto do pretor peregrino. ${ }^{78}$

Todas as ferramentas do processo formular eram contidas nestes editos, isto é, as fórmulas, as praescriptiones, os interditos, entre outros elementos. Todavia, o pretor, tal como não estava vinculado ao ius civile, também não estava vinculado ao seu próprio edito.

Entretanto, apesar de não estar formalmente vinculado às suas promessas, contidas no edito, na prática, eram elas cumpridas, devido à própria pressão social e política da cidade. Daí a prática reiterada do edito tralaticium, o que tornou possível a consolidação de determinados tipos de ações e de instrumentos de proteção concedidos pelos pretores ao longo do tempo. ${ }^{79}$

Todavia, mesmo com o advento da Lex Cornelia de edictis, em 67 a.C., a liberdade do pretor não foi totalmente suprimida, pois, apesar de estabelecer que o pretor deveria atuar de acordo com o seu edito, há notícias de que o pretor ainda podia negar ações previstas no edictum, por meio de um decretum, o que teria prevalecido mesmo após a consolidação do Edito Perpétuo. ${ }^{80}$

A estrutura do Edito do Pretor, no sistema formular, variava conforme se tratasse de ações do ius civile ou do ius honorarium.

No primeiro caso, o pretor simplesmente deveria fazer uma fórmula nos termos previsto no direito quiritário. No segundo, além da formula honoraria, era necessária uma cláusula edital, também denominada edictum, a qual descrevia as circunstâncias nas quais a fórmula pretoriana seria concedida. Desta forma, para ações do ius civile tínhamos a fórmula e a rubrica e nas fórmulas honorárias, tínhamos também a cláusula edital. ${ }^{81}$

Generoso. Edictum Perpetuum. Novissimo Digesto Italiano. Torino: UTET, 1965. v. VI. p. 377 e MACIEL FRANÇA MADEIRA, Hélcio - MARTINS RODRIGUES, Dárcio Roberto. Introdução ao Latim Jurídico - Lucerna Iuris. São Paulo: Quartier Latin, 2005. p. 213-215.

76 O termo album significa branco e é relacionado ao Edito do Pretor, porque ele era escrito em tábua de madeira branca, com as inscrições em vermelho Cf. BRASIELLO, Ugo. Edicta. Novissimo Digesto Italiano. Torino: UTET, 1965. v. VI. p. 371 e FARIA, Ernesto. op. cit., p. 12.

77 BRASIELLO, Ugo. op. cit., p. 371

78 Id. Ibid., p. 377.

79 Cf. MELILLO, Generoso. op. cit, p. 377 e TALAMANCA, Mario. op. cit., p. 145.

80 TALAMANCA, Mario. op. cit., p. 146.

81 Id. Ibid., p. 148-151. O autor ainda acrescenta que, caso a fórmula pretoriana já abarcasse em seu conteúdo os pressupostos para a concessão da ação, a cláusula edital poderia não aparecer. Essa cláusula sempre apareceria nos casos de restitutio in integrum e de missio in possessionem e nunca estaria junto a interditos ou stipulationes praetoriae (promessa de uma das partes mediante, sponsio, de ressarcir a outra em caso de ocorrência de dano dependente de fato futuro). 
No final do séc. I. a.C., sob o comando do imperador Adriano, codificam-se os editos dos pretores existentes até então, trabalho realizado por Salvius Iulianus, ${ }^{82}$ e obtémse o célebre Edito Perpétuo, cuja imutabilidade foi determinada por um senatusconsulto. ${ }^{83}$

A principal reconstrução deste edito é a de O. Lenel, que o divide em quatro partes. A primeira contém disposições processuais até a formação do iudicium, além de versar sobre a calumnia, a in integrum restitutio e a satisdatio. A segunda abarcaria o procedimento judicial ordinário e a terceira, os procedimentos especiais. E, por fim, a quarta trataria do processo de execução e de procedimentos para anulação de sentenças. ${ }^{84}$

\section{Aequitas}

Qualquer discussão sobre a definição de aequitas no Direito Romano deve levar em consideração o seguinte passo de Ulpiano sobre o significado da palavra Direito.

Ulp. 1 inst., D. 1, 1, 1 pr. - Iuri operam daturum prius nosse oportet, unde nomen iuris descendat. Est autem a iustitia appellatum: nam, ut eleganter Celsus definit, ius est ars boni et aequi.

Convém, primeiramente, que [aquele que] irá ocupar-se do direito conheça de onde o nome Direito ${ }^{85}$ se origina. É, porém, chamado de justiça: pois, como elegantemente definiu Celso, Direito é a arte do bom e do equitativo. ${ }^{86}$

E quando falamos em Direito, estamos nos referindo ao direito Quiritário ou ao Direito pretoriano?

Apesar da crítica dos Humanistas a este fragmento de Ulpiano, considerando-o interpolado, pois, para eles, haveria um único Direito imutável em toda a história romana, seria indubitável que o direito mencionado pelo fragmento seria o direito pretoriano, o ius honorarium, pois era ele que, de fato, se apresentava na realidade romana, tornando o ius Quiritium um nudum ius. Sendo assim, a definição de Celso seria de grande valia para a análise dos valores daquela sociedade. ${ }^{87}$

82 Seu nome completo é Lucius Octavius Cornelius Salvius Iulianus Aemilianus (105 - 170 d.C.). Esse importante jurista também foi pretor, em 138 d.C., e era um dos principais representantes da escola sabiniana, sendo rival (mas sem mencioná-lo explicitamente em seus escritos) de Celso, expoente da escola proculeiana. Sua maior obra não foi o Edito Perpétuo, mas os Digesta, com 90 livros, dos quais os primeiros 58 se espelham no Edito Perpétuo e os demais trazem disposições de leis e de senados consultos. Cf. LIEBS, Detlef. Salvio Juliano. Juristas Universales - Juristas Antiguos. Madrid: Marcial Pons, 2004. v. 1. p.172 a 174.

83 Cf. MELILLO, Generoso. op. cit, p. 378.

84 Id. Ibid., p. 379.

85 O termo ius não possui um único significado, como constata GUARINO, Antonio. L'Ordinamento Giuridico Romano. Napoli: Jovene, 1990, p. 97-128, no entanto, adotaremos aqui, ius como equivalente a Direito.

86 Tradução nossa.

87 Cf. RICCOBONO, Salvatore. Ius est ars boni et aequi. Bullettino dell'Istituto di Diritto Romano 'Vittorio Scialoja'. Milano: Giuffrè, 1947. v. VIII-IX. p. 223-235. 
Mas o que significaria aequitas para os romanos?

Costuma-se diferenciar a idéia de aequitas grega da noção romana, sendo a concepção romana mais abrangente, incluindo a noção grega, mas não se limitando a ela.

A definição de equidade para os gregos é apresentada por Aristóteles, na obra Ética a Nicômaco, livro 5,10: "E é essa a natureza do equitativo: uma correção da lei quando ela é deficiente em razão da sua universalidade". ${ }^{8}$

$\mathrm{E}$, neste sentido, a equidade seria o mesmo que epieicheia, isto é, a justiça do caso concreto. No entanto, a aequitas romana não se restringiria a exercer essa função. ${ }^{89}$

Aliás, afirma-se que a noção de epieicheia não se apresenta como o aspecto mais importante da aequitas, e, se alguns autores ${ }^{90}$ incluem a concepção grega na noção romana, outros afirmam não haver relação nenhuma entre os dois conceitos. ${ }^{91}$

Primeiramente, é preciso observar que o conceito de iustum e de iniustum não se confunde com o conceito de aequum e iniquum, pois o iustum, ou seja, aquilo que está de acordo com o Direito, pode ser tanto aequum como iniquum. ${ }^{92}$

No entanto, para os romanos, não havia uma valoração do ordenamento jurídico em si, do ius Quiritium, pois ele não era passível de questionamento, daí a importância da resolução do caso concreto e a percepção de envelhecimento do ordenamento que, apesar de nunca modificado ou revogado, na prática, não era mais aplicado, pois estava em descompasso com as demandas sociais. ${ }^{93}$

Essa percepção de que o ius civile já não correspondia mais ao tolerável socialmente, aparece principalmente com o surgimento de um novo direito, de um ius civile novum, ou seja, do ius gentium. E é neste fato que reside a relação entre o desenvolvimento da noção de aequitas e o aparecimento de um novo sistema processual, o sistema per formulas.

Sendo assim, a aequitas tem por função não apenas corrigir o direito (abrandando as regras do ius civile) na sua aplicação ao caso concreto (epieicheia), mas

88 Cf. ARISTÓTELES. Ética a Nicômaco. Tradução portuguesa de L. Vallandro e G. Bornheim. Victor Civita, 1984. p. 136-137.

89 Cf. GUARINO, Antonio. Equità (Diritto Romano). Novissimo Digesto Italiano. Torino: UTET, 1965. v. 6. p. 620. A noção aristotélica de equidade só seria completa nos sistemas codificados, nos quais somente se corrigiria o direito posto. Cf. RICCOBONO, Salvatore. Aequitas. Nuovo Digesto Italiano. Torino: UTET, 1937. v. 1. p. 213.

90 Como GUARINO, Antonio. op. cit., p. 620 e RICCOBONO, Salvatore. op. cit., p. 213. Já para CARMIGNANI, Maria Cristina. A Aequitas e a Aplicação do Direito em Roma. Revista da Faculdade de Direito da Universidade de São Paulo. São Paulo: USP, 2009. v. 104. p. 117-118, a idéia de aequitas tal como a de epieicheia seriam basicamente idênticas, mudando-se somente a nomenclatura, pois ambos os conceitos refletiriam a noção do justo, da justiça ideal.

91 Cf. BONFANTE, Pietro. L'equità. Rivista di Diritto Civile. Milano: Libraria, 1923. v. 15. p. 191. Pois, para o autor, a epieicheia estaria ligada à noção de conveniência e a aequitas à noção de igualdade.

92 Cf. GUARINO, Antonio. op. cit., p. 620.

93 Id. Ibid., p. 621. 
também adaptar o ius civile e formar um novo direito (ius honorarium), por meio do poder de imperium e da iurisdictio conferida ao pretor. $^{94}$

No Direito Romano arcaico, os conceitos de ius e de aequitas eram convergentes, pois não se poderia conceber um direito que não fosse também equitativo, já que o foco principal da equidade, nesta época, era conferir a mesma disciplina jurídica a todos, daí a importância da conquista representada pela Lei das XII Tábuas. ${ }^{95}$

Mas, com o desenvolvimento e a expansão do império, a noção de aequitas passa a se contrapor à noção de ius, pois esse antigo ius civile não era capaz de tutelar os interesses da sociedade, não sendo por acaso que Gaio, como vimos, afirma que as ações da lei tornaram-se odiosas. Eis que surge um novo sistema processual, proporcionando um aumento do poder do praetor o qual, se não pode modificar o ius civile, pode paralisar seus efeitos. ${ }^{96}$

E, a partir de Cícero, três princípios passam a ser considerados, a saber, o bonum, que é o fim moral do ordenamento, a aequitas, traduzida como o tratamento igual dos sujeitos e a iustitia, representando a unidade entre o bonum e o aequum. ${ }^{97}$

Já no Direito Pós-Clássico e, com a notável decadência da sociedade romana em quase todos os aspectos, há um enfraquecimento dos efeitos práticos da aequitas, proveniente também do fim da atividade criativa seja do pretor (com a elaboração do Edito Perpétuo) seja dos jurisconsultos.

E é nesta fase que a aequitas romana passa a se identificar com os conceitos de benignitas, de humanitas, de pietas e de caritas, revelando nítida influência do Cristianismo..$^{98}$ Desta forma, afirma-se que é essa noção tardia de aequitas que se aproxima

94 Cf. RICCOBONO, Salvatore. op. cit, p. 213-215.

95 Id. Ibid., p. 210. Essa lei origina-se de um movimento plebeu a fim de limitar o poder dos cônsules. Tal movimentação inicia-se em 462 a. C., com o tribuno Gaio Terentílio Arsa e, em 451 a. C., elege-se, com base em um acordo entre patrícios e plebeus, dez patrícios, sob a presidência de Ápio Cláudio, com o fito legislativo. Inicialmente elaboram-se dez tábuas, mas no ano seguinte, acrescentam-se mais duas, surgindo então a Lex Duodecim Tabularum. Cf. AGATI MADEIRA, Eliane Maria. A Lei da XII Tábuas. Disponível em <www.breviarium.net>. Acesso em: 31 out. 2011. p. 4-7.

96 Id. Ibid., p. 211.

97 Cf. GUARINO, Antonio. op. cit., p. 623.

98 BASTNAGEL, Clement. De Aequitate in Iure Romano. Bullettino dell'Istituto di Diritto Romano 'Vittorio Scialoja'. Milano: Giuffrè, 1938. v. IV. p. 360-361, afirma que não se encontra o termo aequitas nas fórmulas judiciais, pois era um conceito reservado somente ao legislador e de forma muito limitada ao pretor. Somente com os imperadores cristãos, principalmente a partir de Constantino, é que o termo se expande e passa a abarcar a idéia de clemência e benevolência. PORCHAT, Reynaldo. Curso Elementar de Direito Romano. São Paulo: Melhoramentos, 1937. v. 1. p. 128-131, menciona dois sentidos para a idéia de aequitas. O primeiro, moderno, identificaria a aequitas com a humanitas e a benignitas, pois a equidade seria aquilo que é conforme ao espírito das leis, atendendo a vontade do legislador, mas de maneira mais branda. Já na segunda acepção, encontrada em Cícero, não teríamos o simples abrandamento do direito vigente, mas a aequitas representaria o princípio supremo do Direito, identificando-se, por vezes, ao ius naturalis. 
do conceito grego de epieicheia, sobretudo, com o advento da compilação justinianéia e sendo essa, pois, a concepção aplicada por todos os sistemas codificados da posteridade. ${ }^{99}$

\section{Conclusão}

A riqueza do Direito Romano está na sensibilidade e na capacidade de se adaptar a novas realidades, com o contínuo e progressivo desenvolvimento de institutos seja de direito material, seja de direito processual.

O tradicionalismo apresentado pela sociedade romana revela-se por meio do respeito aos antepassados, mas, ao mesmo tempo, não os impede de seguir em frente, não limita o gênio criativo dos iurisconsulti e dos praetores.

Quando a tradição impede o progresso e começa a tornar a vida insuportável, os romanos não titubeiam em criar um novo sistema, sem formalmente abandonar o passado. Trata-se de uma revolução silenciosa e paulatina que permite o respeito pelo o que tudo originou e o avanço, para melhor aproveitar o que está por vir.

E foi exatamente esse o motivo pelo qual o sistema per formulas surgiu.

Temos aqui, uma flexibilização do processo a fim de atingir o ideal de aequitas e permitir o continuar da expansão de Roma.

Essa é a idéia que justifica o aumento de poder conferido ao pretor que, com base no seu imperium, atuava conforme as necessidades apresentadas, criando um direito paralelo, um novo sistema, o ius honorarium o qual irá compor a maior parte do chamado ius gentium.

Mecanismos como as praescriptiones, as exceptiones, a denegatio actionis, as ações in factum conceptae, as ficticiae, as utiles e procedimentos como o da in integrum restitutio revelam a preocupação em não só corrigir o ius civile, mas em criar um direito novo, a fim de que o ius fosse sempre a ars boni et aequi.

São Paulo, outubro de 2011.

\section{Referências}

AGATI MADEIRA, Eliane Maria. A Lei da XII Tábuas. Disponível em: <http://www.breviarium. net>. Acesso em: 31 out. 2011.

ARANGIO-RUIZ, Vincenzo. Cours de Droit Romain (Les Actions). Napoli: Jovene, 1935. Pretore. Enciclopedia Italiana di Scienze, Lettere ed Arti. Roma: Treccani, 1935.

99 Cf. RICCOBONO, Salvatore. op. cit, p. 213-214. 
ARISTÓTELES. Ética a Nicômaco. Tradução portuguesa de L. Vallandro e G. Bornheim. Victor Civita, 1984.

BASTNAGEL, Clement. De Aequitate in Iure Romano. Bullettino dell'Istituto di Diritto Romano 'Vittorio Scialoja'. Milano: Giuffrè, 1938. v. 4.

BASTOS MEIRA, Silvio Augusto de. História e fontes do direito romano. São Paulo: Saraiva, 1966. . Processo civil romano. Belém: Falanzola, 1962.

BIONDI, Biondo. Noxa. Novissimo Digesto Italiano. Torino: UTET, 1957. v. 11.

BONFANTE, Pietro. L'equità. Rivista di Diritto Civile, Milano: Libraria, v. 15, 1923.

BRASIELLO, Ugo. Edicta. Novissimo Digesto Italiano. Torino: UTET, 1965. v. 6.

CARMIGNANI, Maria Cristina. A Aequitas e a aplicação do direito em Roma. Revista da Faculdade de Direito da Universidade de São Paulo, São Paulo, v. 14, p. 115-129, jan./dez. 2009.

CRUZ E TUCCI, José Rogério, AZEVEDO, Luiz Carlos de. Lições de história do processo civil romano. São Paulo: Revista dos Tribunais, 2001.

GUARINO, Antonio. Equità (Diritto Romano). Novissimo Digesto Italiano, Torino, v. 6, 1965.

. L'Ordinamento giuridico romano. Napoli: Jovene, 1990.

FARIA, Ernesto. Vocabulário Latino-Português. Rio de Janeiro: Briguiet, 1943.

GIFFARD, André. Études de droit romain. Paris: Cujas, 1972.

KASER, Max, Römisches Privatrecht. Tradução portuguesa de S. Rodrigues e F. Hämmerle. Lisboa: Calouste Gulbenkian, 1999.

LIEBS, Detlef. Salvio Juliano. Juristas Universales - Juristas Antiguos. Madrid: Marcial Pons, 2004. v. 1.

MADEIRA, Hélcio Maciel França, , Dárcio Roberto Martins Rodrigues. Introdução ao latim jurídico: Lucerna Iuris. São Paulo: Quartier Latin, 2005

MARRONE, Matteo. Istituzioni di diritto romano. Firenze: Palumbo, 2006.

MELILLO, Generoso. Edictum Perpetuum. Novissimo Digesto Italiano. Torino: UTET, 1965. v. 6. PORCHAT, Reynaldo. Curso elementar de direito romano. São Paulo: Melhoramentos, 1937. v. 1.

PUGLIESE, Giovanni. Diritto e processo nell' esperienza giuridica romana. Diritto e Processo nella Esperienza Romana. Napoli: Jovene, 1994.

. Obbligazione del capo famiglia e responsabilità diretta del colpevole nel regime della nossalità. Studi in Memoria di Emilio Albertario, Milano, v. 1, 1953.

RICCOBONO, Salvatore. Aequitas. Nuovo Digesto Italiano. Torino: UTET, 1937. v. 1. 
. Ius est ars boni et aequi. Bullettino dell'Istituto di Diritto Romano 'Vittorio Scialoja', Milano, v. 8-9, 1947.

SCARLATA FAZIO, Mariano. Praetor. Novissimo Digesto Italiano. Torino: UTET, 1965. v. XIII.

SURGIK, Aloísio. Lineamentos do processo civil romano. Curitiba: Livro é Cultura, 1990.

TALAMANCA, Mario. Lineamenti di storia del diritto romano. Milano: Giuffrè, 1989.

XXXVI. . Processo civile - diritto romano. Enciclopedia del Diritto. Milano: Giuffrè, 1987. v.

Praetor. Nuovo Digesto Italiano. Torino: UTET, 1939. 